\title{
Vargas Foundation shaping Brazilian bibliographic utility
}

\author{
By Richard F. Phillips \\ Head, Cataloging Department \\ University of Colorado at Boulder
}

\section{Projeto Bibliodata represents a quiet revolution.}

ocated in Rio de Janeiro, the Fundação

Getúlio Vargas is Brazil's major economic research facility. It monitors the leading indicators of Brazil's enormous and complex economy; publishes statistics showing performance in regard to cost of living, inflation, and employment; and advises government and business sectors on such matters. It is one of the most respected voices in Brazil.

\section{Brazilians have the expression "jeito," which translates loosely as "finding a way to get a difficult task done." Bibliodata is an example.}

But there is another side to the Vargas that is impressive and important. Quietly, over the past decade, the Vargas has worked with libraries around Brazil to create the framework for a national bibliographic utility, called Projeto Bibliodata, which now has over 60 member libraries and is expanding rapidly. It offers centralized cooperative cataloging as its main technical service and produces cards and labels, thus revolutionizing the efficiency of processing in Brazil's research librar- ies. Public service features include author/subject/ title searching with a number of qualifiers (such as date, language, and format) as well as boolean limiters.

The membership of Bibliodata spans the Brazilian states. Its most active members are from the southern regions and include the Biblioteca Nacional in Rio, the Universidade Estadual de Campinas in São Paulo, and the Universidade de Brasilia in the nation's capital. However, there are also libraries from Brazil's distant northeast and center, including such notable thinktanks as the Fundação Joaquim Nabuco and the Fundação Gilberto Freyre, both in Recife, and the Universidade Federal de Goias.

Brazilians have the expression "jeito," which translates loosely as "finding a way to get a difficult task done." Bibliodata is an example. Telecommunications in Brazil are unreliable and expensive. For that reason, members are choosing not to maintain dedicated lines into Bibliodata; instead, the Vargas has developed software that allows members to catalog onto floppy disks for loading into the centralized database. A microfiche union catalog is produced, which is consulted by member libraries for cataloging copy.

The Vargas stays on a tight schedule for processing all cataloging transactions, producing catalog cards and labels weekly for shipment by mail. The microcfiche union catalog is updated monthly for 
member libraries. Authority files on microfiche are also updated monthly. These "jeito" activities keep Bibliodata and its members busy. Last summer the database was approaching 500,000 bibliographic records and growing quickly.

The Vargas also mounts other data on Bibliodata. One database called Resete offers timely information on the Brazilian economy and trends in relation to agriculture, industry, and commerce. Demographic indicators allow researchers to study the nation's population. The data, produced by the Vargas Foundation, is regularly reviewed and updated.

The future is uncertain for Bibliodata and the Vargas. Inflation in Brazil for the period of September 11-October 9, 1990, was estimated at $12 \%$, allowing projections of about $150 \%$ inflation since the new government took control in March 1990.' That figure represents a sharp drop from the approximately $600 \%$ rate of inflation the previous year. The change is due to the strict austerity measures of the Collor government, including a total freeze on all commodity prices and salaries across the nation. Government agencies are facing $25 \%$ cuts in their budgets. The situation is exacerbated by heavy dependency on oil from the Persian
Gulf, which places great pressure on Brazil's shaky but favorable trade balances.

The Vargas is not immune to economic stresses, having experienced labor walkouts recently. Money for research, system development, and equipment needs will be hard to find. ${ }^{2}$ Member libraries are in similar situations. Many would like to offer online services to their users, but face cost restrictions that make use of Bibliodata for reference and interlibrary loan limited if not impossible.

Nevertheless, Bibliodata is an impressive achievement and offers efficiencies in information technology. As such projects are further developed and electronic links are established within Latin America and beyond, the significance of Bibliodata will be more obvious. Already plans are being discussed for tape exchanges with the Library of Congress as well as a number of European agencies.

"Management Alert," Business Latin America, October 15, 1990, 332.

${ }^{2}$ Interview with Eugenio De Court, director of Projeto Bibliodata, in Rio de Janeiro on June 14, 1990.

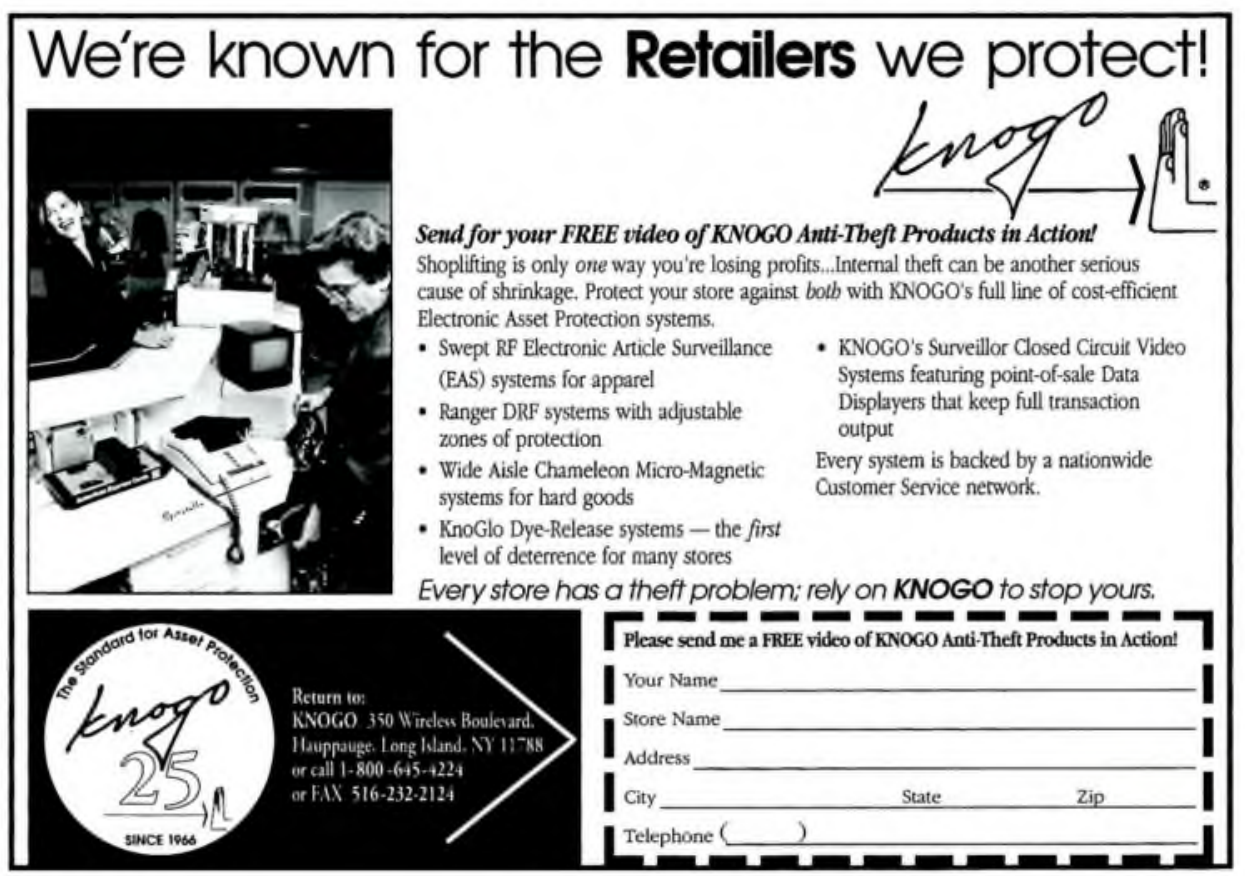




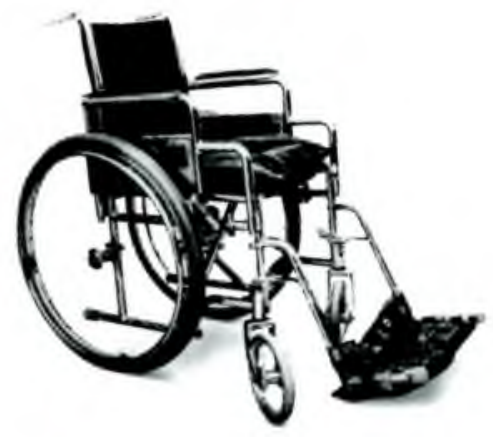

From disabilities to penalties,
no one looks at the world like PAIS

From disability benefits to capital punishment, there's one place you'll find the spectrum of political, economic, and social issues sitting side by side - PAIS.

The PAIS index provides global coverage of today's most important issues and concerns: international trade and relations, the environment, business and finance, and education, to name just a few.

Within seconds, you can explore a huge range of books, periodical articles, government documents, statistical compilations, and other items from all over the world.

And, you can gain fresh perspectives and a deeper understanding of international

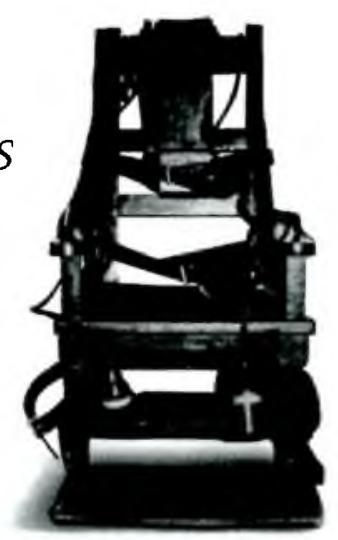

concerns via stringently edited references to literature published in English, French, German, Italian, Portuguese, and Spanish.

Best of all, PAIS gives you the information you need in the format you like best: CD-ROM, online, or the new PAIS International In Print, a continuation and enhancement of the PAIS Bulletin.

Make your research faster, easier, and more productive with the one index that covers the spectrum of political, economic, and social issues - PAIS.
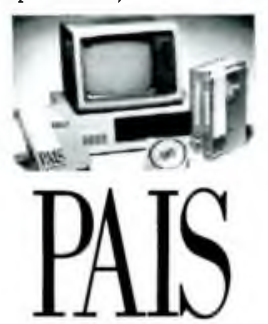

Public Affairs Information Service, Inc. 521 West 43rd Street New York, NY 10036-4396 800-288-PAIS, 212-736-6629 (in NYC) Fax: $212 \cdot 643-2848$

No one looks at the world like PAIS

In Print PAIS INTERNATIONAL IN PRINT • PAIS SUBJECT HEADINCS Online: PAIS INTERNATIONAL ONLINE On Compact DisC: PAIS ON CD ROM 